\title{
Indian Health Care and Insurance Industry on the Eco-System of a Digital Transformation
}

Prof. Amruthamma R, Research Scholar, Bharathiar University Assistant Professor,GFGCMalur, Amrutha.r99@gmail.com

Dr T Ashwatha Narayana, Research Guide \& Assistant Professor GFGC, K R Puram, aswath@gmail.com

\begin{abstract}
:
Digital technology has led to a global revolution. The world is becoming increasingly more connected and is able to solve more and more complex societal problems through increased collaboration and information sharing. Technologies ranging from the most common smart phones to clinical advancements in $3 D$ printing have driven this trend and continue to evolve over time. As a result, digital oriented consumers have already increasing the traditional consumers. The study is about comparison with the tradition method and digital method with the advantages as opportunities and challenges in the health care sector. The study goes with the objective , Research methodology is based on primary data and secondary data with analysis and conclusion. The study gives the technological advantage in reaching the social media and its growing GDP and expansion in the healthcare is an added possibility to expand. Accessibility in the rural sector through digital connectivity and more wearables. The rise of digital technology is pushing India to achieve Health for all, putting the country at the forefront for foreign investment. With these opportunities, India is emerging as the global leader in digital health.
\end{abstract}

Key words: Accessibility, Wearable's, Digital Transformation

\section{Introduction}

The online insurance industry in India is witnessing a phenomenal level of growth for the past few years. On insurance front, people started relying on internet to research about the kinds of products. However, with each passing year, digital insurance industry gradually expanded its footprints in India and therefore, online mode is not limited to just research and insurance comparison.

In today's scenario, Indians have the confidence to purchase online protection policies. They buy, renew, make payment of premium online and even avail postpurchase services.Insurance sector started to penetrate the digital platform in the year 2005 . Everything began with the concept of online comparison and research of insurance policies and this was made possible due to some web aggregators.

Web aggregators provided extra comfort to buyers by letting them compare policy online policy Bazzar for the comparision of the products. Though, it was never easy to persuade researchers to buy policies through online mode. Nevertheless, transparency and safe payment gateways influenced more than half of the researchers and appealed them to make a purchase. Insurers also recognised the imprint online mode had made on the minds of consumers and therefore they initiated to promote online term insurance quotes and policies. In 2010-11, most of the insurers started selling online. And at present, insurers have made online mode a priority in their distribution strategy. Though, many insurers are still focusing on term plans, but a few of them have moved ahead beyond term and car policies.

Digital insurance in different places

Interesting fact explored in reports states quite 
significantly that previously large amount of sales came through metros and tier 1 cities. However, now people from even the mid-level cities like Indore, Jaipur, Lucknow and Surat and other tier II and tier III cities are interested in buying.

There were around 165 million internet users in India in 2014. This figure has reached around 200 million this year. Online purchase of policies has increased from 2 percent to 200 percent in just two years. Looking at this, the growth rate of the online industry in the years coming ahead is expected to be in three digits.

If a report from management consulting firm like BCG is to be believed, digital insurance will skyrocket to Rs 15,000 crore by year 2020 .

This research implies that the industry is enjoying a growth of 2000 per cent in the next five years. It has been estimated that online sales contribute around Rs 700 crore to the total turnover of the industry altogether.

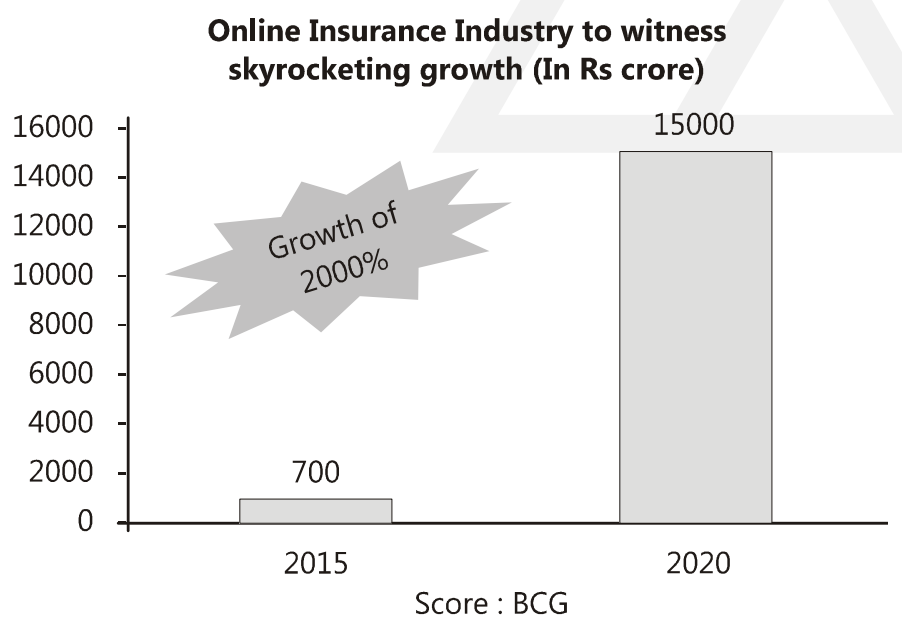

If this number is projected to reach Rs 15,000 crore, then the industry is going to multiply its online sales 20 times. That's an amazing inference!.

More and more people are coming under the ambit of e-commerce and this trend will continue moving northwards. With the government of India itself supporting digitisation, the level of trust will go up.
So, there is no looking back for a sunshine industry like insurance, which is already experiencing a phenomenal growth.

As per the BCG report, life segment garners almost 45 per cent of the total online insurance market. Vehicle protection is the second largest segment contributing Rs 250 crore to the total sales of Rs 700 crore. The other segments such as health and travel secure the remaining piece of the cake.

\section{The digital impact}

As per industry research and analyses, it is said that in the 2-3 years, three out of every four insurance purchase decisions will be influenced by digital channels of sales and marketing.

Digital is an overarching structure and online insurance sales is a part of it. Digital insurance also encompasses use of digital technology to not just promote the services but also to enhance the overall customer experience. It is also about efficiency and setting up systems and processes.

Online sales, is though a tangible aspect and an insurer can quantify the impact of its online marketing efforts.

\section{Consumer interests}

When it comes to the Internet, Google is one of the most credible force. Recently, this search engine giant conducted a study to analyse consumer trends over online platforms and found that since 2008 , a number of people have been searching for life and health insurance policy comparison and related information online. This trend has grown by 450 per cent. The general insurance industry rather witnessed a cumulative growth rate of 600 per cent in the past five years.

These numbers reflect the magnitude of digital insurance in India and act as a testimony to the success of online channels. 
The latest trends seen in the insurance industry are as follows:

\section{Online insurance}

Over the last few years, the shift to online insurance has brought to the customer a large number of protection and savings solutions that were not available earlier. Connectivity and the shift to mobile e-commerce will soon play a significant role in the sector. Increasing use of mobiles and mobile apps is impacting how companies conduct business and interact ..

\section{Big data and analytics}

Big data and analytics provide valuable and actionable insights. Big data plays an important role in risk management, enabling companies to analyze risk characteristics and claims statistics. Big data helps companies monitor brand reputation by analyzing comments in social media. By doing so, companies can immediately address issues that may damage their reputation or brand

\section{Training insurance agents}

Agents are one of the trusted channels for selling insurance products. Insurers are increasingly investing in training and education of agents in order to enable them to deliver better service to customers.

\section{Social media and collaboration}

Social media is about helping people connect. Social media platforms such as Facebook, LinkedIn and Twitter, are frequently used in marketing to drive brand.

\section{Distribution channel management}

In a multi-channel world, existing distribution channels remain as new channels emerge, complicating channel management. Today they are managed as discrete distribution channels unable to integrate for seamless interactions. Different elements of insurers' communications are shifting at different speeds and older channels are not going away. This increases the burden and confusion for insurers, who are required to invest in support .
The increase in internet and mobile usage can be major influencers in shaping customer preferences and research of products online. While Indian consumers still believe that getting advice from an agent is an important part of purchasing insurance, observation says that online research on health insurance has shown an increasing trend.

With a population of around 1.3 billion, India is the second most populous country in the world. A large percentage of its population is youth population. Young people are the innovators, creators, builders and leaders of the future. However, they can transform the future only if they have skills, health and information to enable decision-making and real choices in life. Internet usage is growing rapidly mainly because of young users and technological innovations. Mobile e-commerce.

\section{Digitalisation in insurance industry}

From claims made for natural calamities to everchanging consumer behaviour, the insurance industry has seen it all. The current challenge they have in hand is to adapt digitalisation. The insurance industry today is standing at a transformative stage, where people's buying methods have changed. Initially, sales executives used to walk door-to-door, selling insurance products. As insurance-related documents were too complex, people preferred to buy insurance plans recommended by someone instead of researching the best insurance plan available for them in the market. However, this scenario will change as India is progressing towards digitalisation. People will now look for insurance plans online, compare, research, and buy them online. They can even submit documents online with an e-sign.

\section{Benefits of Digitalisation to Insurance Providers}

These days people prefer to transact online as much as possible. From booking a movie ticket to applying for a car loan, they do it all online. The same applies to the insurance sector. With the march towards digitisation, many customers are going to buy insurance plans online which will change the marketing channels of insurance companies upside 
down. Some of the benefits of digitising the insurance sector are as follows:

Reduces salary costs: Insurance companies recruit hundreds of sale executives every year to sell their insurance products. If customers are reachable online, insurance companies will reduce the number of door-to-door sales executives which will reduce the salary cost of the company.

Increases the target group: Going digital increases the scope to meet many customers. The target customer base increases and insurance companies have the opportunity to pitch their products to many people.

Convenience: Accessing insurance products online is convenient and less time consuming. On the other hand, insurance companies can sell their products online without much struggle.

Less paperwork: Both insurance provider and policyholder don't have to go through the tedious documentation process. Documents can be shared and saved online.
Hassle free claim settlement: The main problem that arises when making insurance claims is incorrect or non-availability of documents. With digitalisation, this problem can be eliminated as all documents are saved online and are accessible for both the insurance provider and the policyholder.

\section{How Digital Firms Create Value}

Insurers are already demonstrating the value that a digital approach can deliver through improved connectivity with clients and intermediaries, better decision-making, cost savings from automation, and as a springboard for business model innovation. The choice insurers face today is whether to simply invest in digital capabilities or become digital insurers. The bestperforming carriers of tomorrow will choose the latter course. Based on work in the insurance industry and cross-sector research on the qualities digital leaders have in common, 1

McKinsey believes carriers should rethink their approach in six areas where digital can have the greatest impact: strategy, customer-centricity, business processes, organization, technology, and analytics and decision-making

Data from both internal and external sources is gathered in real time and mined for actionable insights.

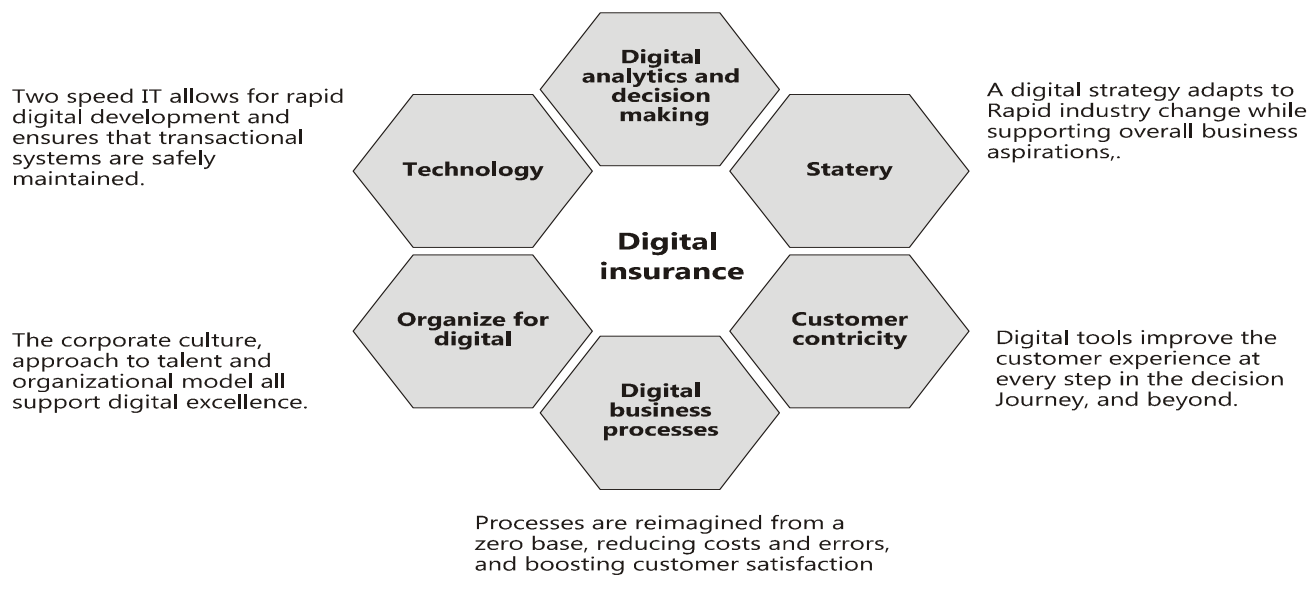

Insurers can use digital tools to develop a clear view of which customer interactions can be re-imagined through digital, which are frustrating for policyholders or insurance shoppers, and where an improved experience will have the most impact. 
Technology advances are transforming different industries at an ever-increasing pace. In-surance industry will not be isolated. These advances will be a lot more potent as they will have widespread applications across different aspects of the insurance business including sales, underwriting, claims and customer service.

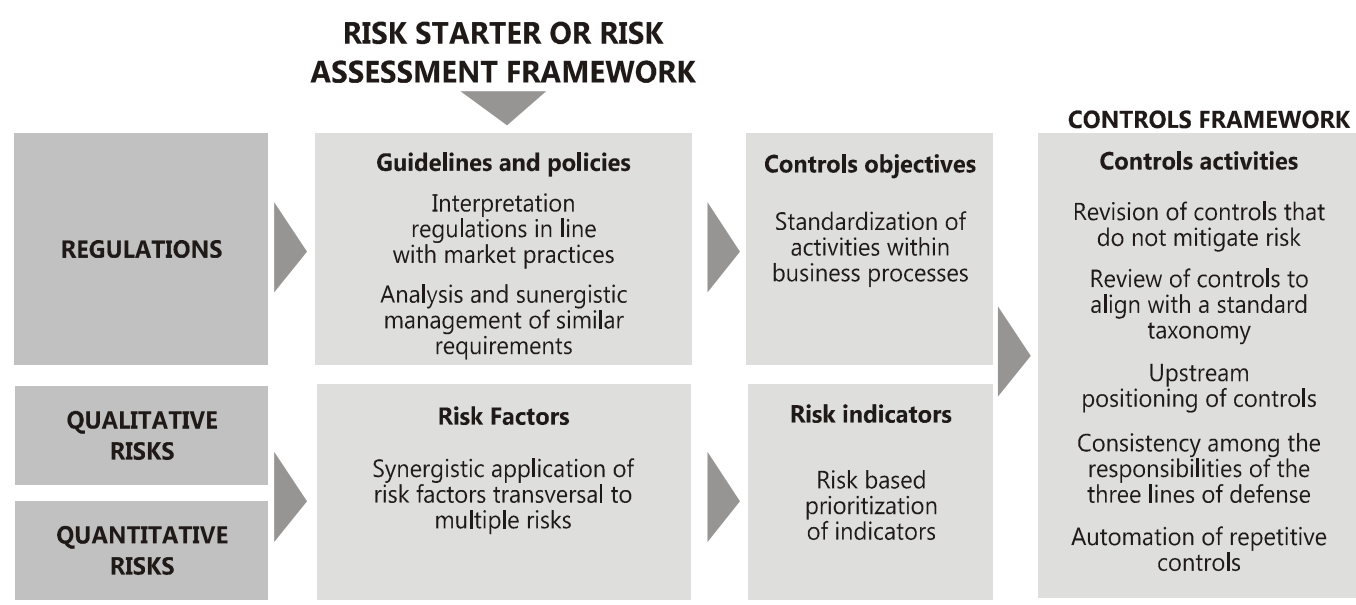

Source BCG Analysis jan 2017

Direct digital interaction with customers: In the last few years, online insurance aggregators, email and social marketing, search engine marketing and website + tele-assist based direct sales have established themselves as key digital marketing and distribution channels. Growth witnessed in these channels leaves no doubt about their potential. By leveraging analytics and advances in technology and digital infrastructure, direct digital interactions and marketing to the customers will become highly personalized, more engaging and automated using natural language processing.

\section{Ecosystems and partnerships a reality-leveraging the broader ecosystems}

To create 'sustainable' differentiation, insurers will need to think of new business models that are hard to replicate and that engulf the customer across broad needs fulfilled by a suite of services. For example, creation of health ecosystem vs. health insurance, mobility ecosystem vs. motor insurance, retirement ecosystem vs. pension plan, child care and development ecosystem vs. health insurance and so on. Ecosystems are a set of businesses, which address customer needs in a comprehensive and integrated manner.
For example, a health ecosystem will entail wellness providers, health food providers, fitness centers, primary clinics, diagnostic centers, secondary or tertiary hospitals, payers such as insurers / corporate / government, pharmacies, disease management services linked together by an ecosystem aggregator. Ecosystems will help not only in gaining share of wallet but also in achieving customer 'lock-in' with more hooks and hence high exit barriers. Insurers will have to either take the lead and create such ecosystems or participate in existing ones. Since ecosystems business model is radically different from traditional insurance business model, it will require insurers to take large strategic bets, heavily invest in product design, operations and technology and source customers through multiple touch-points across the ecosystem.

\section{Process digitization -Customer journeys will be digitized end-to-end}

The global trend of digitizing the core insurance processes of sales, claims settlement as well as backoffice operations is also gaining roots in India. A number of insurers have launched processes and apps for distribution partners and customers. Apart from productivity gains, digitization also helps improve 
process quality through standardization, process risk controls and lower manual involvement.

For process digitization insurers will leverage the rapidly developing digital infrastructure in the country as well as the latest technological advances. The next advance in process digitization will be driven by the following five key elements:

Aadhaar based biometric authentication: Recent entrants in banking and Telecom have already leveraged Aadhaar based authentication to roll out fully paperless customer on-boarding process with high quality KYC compliance. Insurers have also started using the same. The time has come to commit to this unconditionally.

Digital document storage: Whether it is dematerialized policy documents or claim documents, insurers have the opportunity to eliminate paper from most, if not all processes. However, to take full advantage, it will be imperative to have data architecture that allows capture of semi-structured and unstructured data. Third party digital lockers are now a reality where users can allow insurers to access paper records issued by other third parties such as government or medical records.

Digital consent: Insurers in future will increasingly use third party data for tailored offerings, underwriting and customer service. Digitally signed consent through a modern private data-sharing framework will allow insurers to securely access specific data allowed by users. It will also enable separation of data and consent flow reducing the chance of frauds.

Digital payments: Accelerating transition to cashless economy and adoption of UPI interface will significantly enable process digitization and eliminate manual elements of payment collections.

New technological advances: Internet of Things (IoT) including wearables and telematics devices, Artificial Intelligence (AI) including chat-bots and machine learning, and Robotics will significantly increase automation leading to greater productivity.

\section{Customer engagement -Digital will enable customer centricity}

Insurance as a product category faces a key challenge of limited customer touch-points and low customer engagement despite the consultative nature of the product and significant financial implications for the customers. BCG experience shows that insurers have on an average of 0.3-0.4 customer contacts per year. Add to that, the Indian situaThe Boston Consulting Group.

tion where so far, insurers have focused more on intermediaries than the customers, has resulted in even less data on end customers. Customer contactability is abysmally low.

Digital is a key enabler of disintermediation and allows insurers to meaningfully engage and influence customer experience directly. Insurance companies will have to start treating end customers as customers. They could potentially leverage the opportunity to integrate other high frequency transactions such as financial dashboards, health apps, social media content or other customer journeys (e.g. driving, travel, child education) and create 'moments of truth'. The next imperative will be to excel at customer experience in those interactions. Insurers that will crack the code will surely have a better chance of increasing customers as well as share of customer wallet and retain customers for longer.

\section{Products and pricing -new, tailored and integrated end-to-end}

In the rapidly evolving world, we believe that products will evolve on three key dimensions.

New products-Evolving needs and growing niches will drive new product development and product feature enhancements. E.g. cyber risk, fine arts, extended warranty products will become more prominent.

Tailored offers-based on data insights will make products uniquely relevant to the segment of one and pique customer interest. Better understanding of the 
customer profile and life stage, other financial transactions, social behavior will allow insurers to provide the 'right product at the right time'.

Products integrated with partner offerings: Insurance is already sold through partnerships as an attachment product primarily in the context of loans or large asset purchases such as housing and vehicles. Even further, insurers will have the opportunity to introduce products with features that are highly customized or integral to the partner's product offering.

Product evolution will go hand in hand with evolving pricing approaches. Pricing will be a key driver of profitable growth. New data sources such as partnerships, loT - wearables, big data analytics, will put insurers in a great position to bridge the 'data divide' and price products appropriately.

\section{Data and analytics will be king and will differentiate winners from also-rans}

Like other businesses, insurers are also keen to leverage big data analytics. However, they suffer from lack of quality data. In India, the challenge is even starker, insurers struggle from lack of data, leave aside high quality data. It is driven partly by the nature of the business where customer transactions are limited (BCG analysis shows just about 0.3-0.4 contact points per year) and partly by the focus of insurers on intermediaries who call the shots and at times mask the data and do not share the full customer data with the insurers. In general in-surance, for example, since KYC is not mandatory, insurers often do not have basic profile information of the customers.

Importance of data is beyond debate and insurers can overcome the challenge by first looking internally for the right processes to capture the appropriate data as well as look at forging data partnerships. Different data partnerships become relevant in the context of sourcing and actuarial modeling. In case of sourcing, insurers need to dig deeper into sourcing data from intermediaries apart from third party partnerships which provide rich information on customer profile, life stage, social behavior and transaction context. In case of actuarial modeling, varied sources of data can be leveraged in specific contexts. For example, weather data can not only be used for crop insurance but also for analyzing chances of health epidemics, public health issues (e.g. pollution), natural disasters impacting life and property.

\section{Creating the technology and data architecture required to deliver the 'digital insurer'}

Infomation Technology has been the backbone of many transformations within the Insurance industry over the past two decades. However, the past two decades will not be a patch on the next few. The multiple state-of-the-art technology advances from big data and analytics, to machine learning and artificial intelligence, to the Internet of Things including wearables and telematics, to robotics, to chatbots, to voice recognition and beyond, will completely transform the requirements from IT architecture. Agile, a very small five alphabet word, will drive the technology teams crazy. Let's take just two of these advances as examples, Al and Big Data.

Incorporating technological advances - The stack of Al services has become reasonably standardized and is increasingly accessible through intuitive tools. Even non-experts can use large data sets. Right platforms and tools need to be setup for flexible architecture and for integration with diverse process elements.

As insurers prepare themselves to leverage Big Data either by harnessing data that is available internally or through partnerships, they need to assess the preparedness to manage such data. Traditionally, insurers have been used to managing structured data that comes as part of various business processes. Harnessing new sources of data will require the ability to store and process semi-structured and unstructured data such as customer interactions, images, medical records. Multiple trade-offs including costs, speed, functionality, scalability, data diversity are involved while choosing the right data architecture in line with business objectives. Given the selection and implementation lead times, this becomes not only 
important but also urgent for parallel design and execution of business strategy.

\section{Ride the wave of regulatory shifts - be agile and ahead of the game:}

In case of the insurance industry across the globe, regulatory changes have always had large implications for insurers. As one looks ahead, the regulatory environment will continue to be dynamic because of the business environment changes, such as new business models like the ecosystems mentioned above, new products driven by partnerships and customer data insight, heightened risks such as cyber security and data privacy. Insurers will need to keep pace with the evolving regulations.

Take for example, the GST rollout, which is likely to happen this year. This will have a huge implication for insurers on multiple fronts, including attractiveness of product categories, and the operational efforts for insurers. The applicability of different GST slabs can significantly influence affordability and therefore alter the growth trajectory of different product segments.

Insurers will need to work with the regulatory body to ensure that regulations, while aligned with the principles, are also practical in terms of the implementability, the impact on customers and the business economics.

\section{Value creation in changing shareholder world:}

A number of the insurers will have to deal with new shareholders over the next few years.In fact, likely all of them. Two big trends driving this - the listing of insurers, including the PSUs and the accelerating wave of $M \& A$. Retail investors (driven by listing), new strategic investors (basis $M \& A$ ) and potential $P E$ investors are all going to completely transform shareholder expectations. The scrutiny on the insurers as well as the many metrics will change drastically. Typically, not only value creation, but also consistency of the same (beta) is key for investors. Insurers will have to manage these new shareholder expectations. Insurers will need to place their bets on the most relevant priorities for them in the context of their business model and pursue them with conviction.

The Changing Face of Indian Insurance steps in the value chain

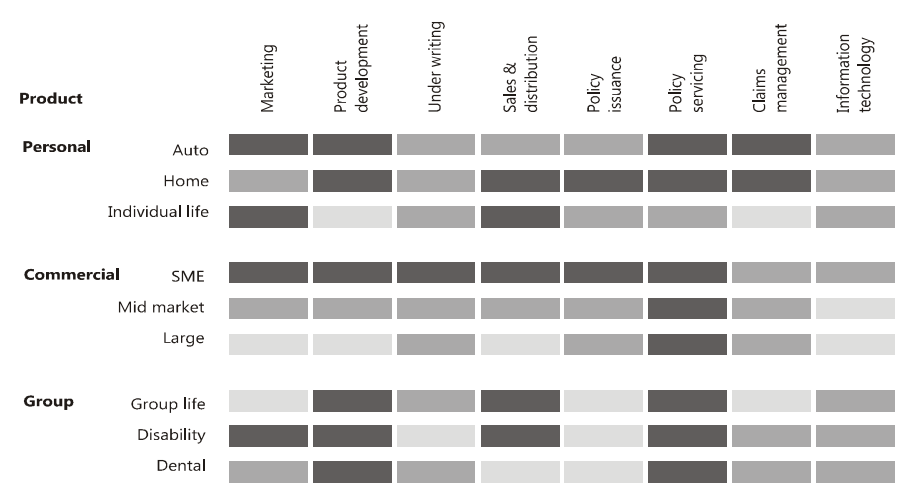

Consultative regulator approach to improve insurer confidence

\section{- Eliminating standard prescribed expense limits :}

Under the old provisions, an insurer's annual management expenses had to be within prescribed

limits, restricting its ability to diversify into untapped geographies and entailing a high cost of setup. This clause has been eliminated, giving more power and flexibility to the local regulator (Insurance Regulatory and Development Authority, or IRDA) to regulate management expenses and prescribe a broad architecture to determine expense limits.

- Flexibility on maximum commissions to agents: Previously, the maximum amount of commission payable to an insurance agent or intermediary was prescribed. This was done to contain inorganic growth by insurers that could compensate intermediaries significantly for business. In reality, insurers created alternate routes by making high distributor payouts.

In response to an already prevalent practice, the commission payout restriction has been dropped.

Instead, the regulator will regulate the commission at a product level, thereby ensuring that productmargins are met. 
This has no direct impact on customers; however, the flexibility of commissions could set a trend forintermediaries to push a particular product that has higher allowable commissions. As insurers restrictthese commissions at will, there could be a significant reduction in earnings. Nonetheless, considering the dependency on distribution in India, insurers likely will modify their model to ensure that distributors are compensated adequately. Greater flexibility in managing expenses and commissions could also lower an insurer's expenses.

\section{- Withdrawing the requirement to deposit with the Central Bank}

Insurers were required to maintain a deposit of US $\$ 1.5 \mathrm{~m}$ with the Central Bank of the country. In the amended bill, this requirement has been waived, offering flexibility to new insurers with a lower topline to deploy this additional fund effectively.

\section{- Eliminating renewal commission to non- agents}

The amended bill has provided a good response to the burning issue of high agency attrition,

impacting both productivity and activity. In the earlier provisions, an insurer was required to

continue paying renewal commissions to an agent who had served a minimum of five years with the company, regardless of whether he or she was still an agent. In the amendment, insurers are not required to pay agents who cease to be their agents.

\section{- Responsibility for appointing advisors is entrusted to insurers}

The new regulation empowers the regulator to regulate the agent's eligibility, qualifications and other aspects. In lieu of this, insurers now have the sole right to appoint agents without regulator intervention. The sudden change from the IRDAled approach of hiring agents will demand the establishment of a better training architecture to effectively manage the surge in agent volume internally and ensure robust processes.

\section{Customer-centric outlook allows banks to operate as insurance brokers}

IRDA's Regulation, 2013 (Licensing of Banks as Insurance Brokers) enabled banks to enter the business of insurance broking. As of January 2015, the Central Bank allowed banks to act as brokers for insurers, set up their own subsidiaries and undertake referral services for multiple companies.

Increase in transparency in insurance sales: banks acting as brokers holds multiple advantages for the customer. As corporate agents, they represent the interests of the insurer, and as brokers, they have direct fiduciary responsibility for selling insurance policies. To fulfill this responsibility, banks must inform the customer about product benefits to assist them in making an informed and educated decision. Customers will have more options in each product category with banks selling the products of multiple insurers. This will also compel insurers to design customer-centric, competitively priced products.

New distribution opportunity for insurers: those with no bank tie-up because of the earlier agency model, have an opportunity to forge new relationships and shore up their bancassurance channel. Such insurers will gain access to a much wider audience for their products, thus helping them enter underpenetrated markets.

While these guidelines offer a fresh ray of hope for the stagnating bank channel, this change mandates a high level of preparedness to approach customers. This will require significant investments in training bank staff, advanced IT platforms and servicing.

\section{Introducing IMFs as a new distribution channel}

The regulator recently finalized the guidelines for IMFs, which will be a new distribution intermediary for selling insurance products. IMFs will be allowed to solicit and sell products of two life, two nonlife and two health insurers. Additionally, they also will be allowed to sell other financial products, such as mutual funds, the National Pension System, and banking and financial products of banks and nonbanking financial companies. IMFs will have a 
fiduciary responsibility to policyholders and must perform a needs analysis of their clients, compare products of insurers they have aligned with and

recommend products based on clients' needs. This will provide for high-quality sales and eliminate any chances of mis-selling.

The lower capital requirement for establishing an IMF, combined with its potentially being a one-stop shop for all of a customer's financial needs, makes it a lucrative choice for independent financial advisors and certified financial planners. For insurers, IMFs can be an effective distribution channel to help increase the footprint in untapped segments without a significant capital drain.It will also help revitalize the stagnating role of agents,

who now can become financial advisors and run their own distribution organizations. This will reinforce the "old-time charm" of the agent profession.

\section{Fiduciary responsibility and accountability mandated to customers}

The regulator often has taken steps to protect policyholder and customer interests by mandating processes, reporting requirements and imposing penalties. However, the new bill has further tightened this in the following ways:

\section{Stage of maturity}

Governance: under a provision of the Insurance Laws (Amendment) Bill, 2015, no life insurance policy can be questioned on any grounds for three years from the effective date of the policy. This mandates a need for strong sales and underwriting processes.

Intermediary accountability: insurers are now responsible for all acts and omissions of their agents, including violation of the code of conduct specified by the regulator. This mandates closer monitoring of intermediary activities.

Increased penalty: insurers are liable for a penaltyof up to US\$150,000 for the acts and omissions of their agents. Similarly, a standard penalty of up to US\$3.8m has been included for failing to comply with the obligations of the rural or social sectors or TP insurance of motor vehicles. This may see some insurance companies implementing business strategies to comply with the obligations, thus resulting in increased rural penetration levels.

The regulatory and legislative environment that is conducive to growing the economy and continuing its lucrative proposition for foreign investments is already reaping benefits. With a host of activities in the insurance investment space and expectation of further interest from several foreign insurers, this industry is poised for growth.

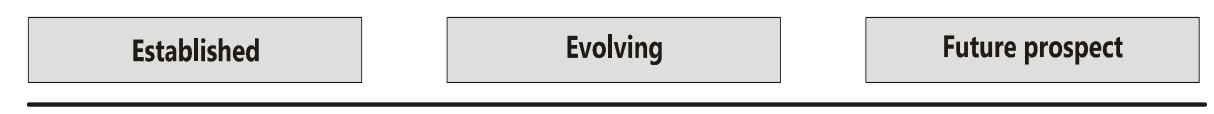

Trends and future anablers

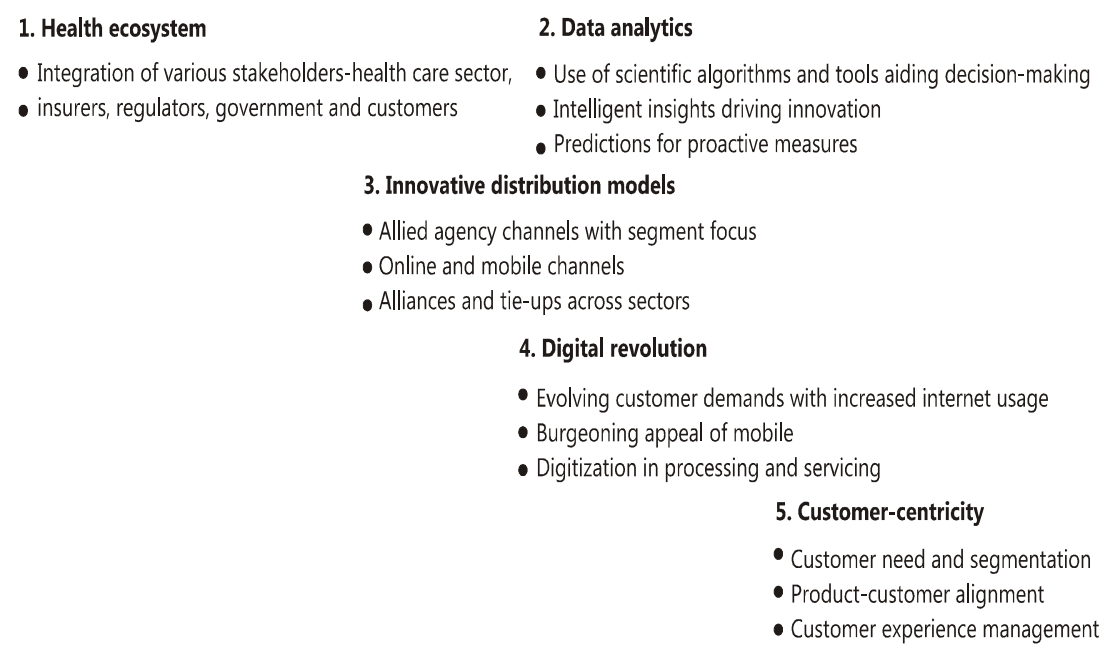




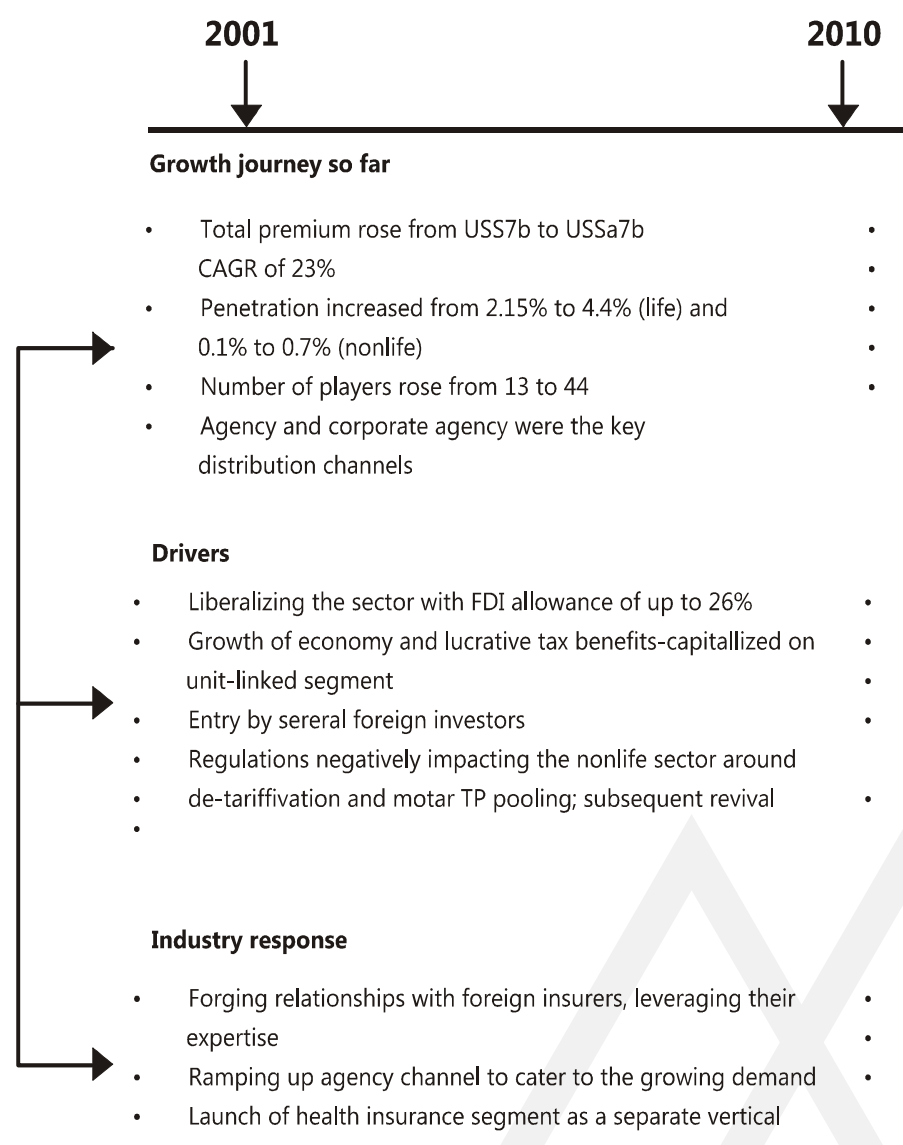

Future enablers and trends

\section{Health ecosystem}

Increasing awareness levels, inflationary health care costs and the rapid progression of medical technology are creating an untapped market potential. This requires building an ecosystem in collaboration with health care, insurers, regulators, government and customers.

\section{Enablers:}

- Health care sector: improve infrastructure to increase ties with third-party administrators, including IT integration and standardizing policy wording and rates, enabling insurers to better price their products and manage claims

- Insurance companies: improve customer servicing capabilities for claims management and enhance product-design focus on different segments and risk-based pricing to increase market penetration

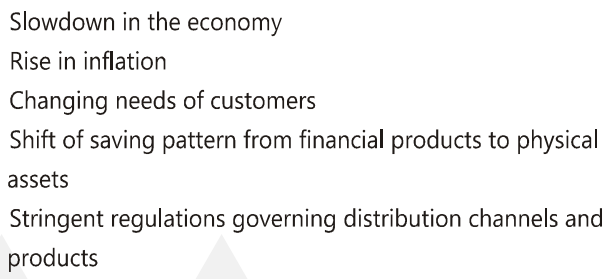

Exploring alternate channels for cost-effective distribution shift in product mix from unit linked to traditional

Digitization to enhance customer focus and plug leakage

- Regulator: continue to protect policyholders interests through health insurance products and expand efforts to include product innovation, better processes in group claims management, microsegmentation and the creation of a central repository of information

- Government: several government initiatives through state government schemes have been launched in the past; however, awareness about the inclusions within these schemes remains low. The new government has launched new schemes to cover the masses though only a consultative approach with insurers and other providers will help spread awareness so that the intent of providing these offers reaches the right target segments.

Customers: customers need to be proactive in understanding their basic needs and not just depend on an exigency or their corporate covers. Alongside 
legislative reforms, the vision for a profitable future is supported by current trends and future enablers, which will play a pivotal role in the industry. These trends and enablers are at different stages of maturity, including established, evolving and futuristic.

\section{Conclusion:}

Insurers worldwide are increasingly creating value by using digital tools and technology in a number of innovative ways. However, much of the potential value and the most significant opportunities for making digital a competitive advantage remain untapped. To unlock this potential, insurers should follow the example of leaders in digitally advanced industries, which take an enterprise-wide approach to digital and understand that digital is more than the sum of individual initiatives. In short, to reap the full benefits of the digital era, insurers should aspire to become digital firms. 